$$
\begin{array}{cl}
\text { Journal of Translation and Language Studies } & \text { J Trans \& Lang Stud } \\
\text { jtls.sabapub.com } & (2020) \\
& 1(1): 37-48
\end{array}
$$

\title{
Grammaticalization of some Postpositional Enclitics in Kanuri written Texts
}

\author{
Baba Kura Alkali Gazali ${ }^{1, *}$ \\ ${ }^{1}$ Department of Languages and Linguistics, University of Maiduguri \\ Received: 03.10.2020 • • Accepted/Published Online: 15.11.2020 $\quad$ • Final Version: 15.11.2020
}

\begin{abstract}
This paper examines the strategies and concepts of postpositional clitics in Kanuri. clitics in Kanuri within the broad framework of descriptive linguistics. The study adopts the works of Zwicky and Pullum (1983), Anderson (2005) and Spencer and Luis (2012) as its analytic models. The primary sources of data collection are Kanuri written texts: Səmonəm wuro sarugəsəne by Norbert Cyffer and Nyariwa Kanuribe by Shettima Bukar Abba and John Hutchison. These two texts are collection of stories written in the Yerwa dialect of Kanuri. All the various places where the postpositional particles -ro, -lan,ma and -ga occurred are identified and extracted for presentation and analysis. The outcome of the study reveals that these particles can be encliticized to lexical words in Kanuri to express different functions. These particles -ro, lan, ga and ma virtually attach to every grammatical categories of words in Kanuri i.e. nouns, adjectives, pronouns, verbs, adverbs to express different functions while the Emphatic =ma can be used as focus marker in Kanuri
\end{abstract}

Keywords: Kanuri; clitics; postposition; enclitics; particles.

\section{Introduction}

Kanuri is a member of the Saharan branch of Nilo-Saharan phylum of African languages (Greenberg, 1963). Bendo (2000:44) presents the Saharan branch according to the following grouping: Saharan: Kanuri- Kanumbu, Daza, Teda-Tubu, Zaghawa-BedeyatBerti. Lewis (2009) presents the Saharan branch into Eastern, Western and Northern branch. Kanuri, Tebu, Daza and Teda are classified under the western branch. Kanuri anguage, according to Cyffer (1998:11) is the widest spread language in the Lake Chad region and is spoken in all the countries bordering the Lake (Cameroon, Chad, Niger and Nigeria). According to Bulakarima and Shettima (2012) there is also few members of Kanuri speakers in Fezzan (Libya), some Kanuri in diaspora also live in Sudan, mainly having settled there on their way to pilgrimage and in the area around Khartoum. The estimated number of Kanuri speakers in Nigeria is between four and five million, those in other countries do not exceed one million. Bulakarima and Shettima (2012) further observe that Kanuri is the major language of the people of present-day Borno and Yobe states in Nigeria. Kanuri speaking groups are also evident in other parts of Nigeria (e.g. Alkaleri, Azare, Gamawa amd and Misau Local Government area of Bauchi state, Lafia in Nasarawa

\footnotetext{
* Corresponding Author: babakuraalkali1974@gmail.com
} 
state, Kirikasamma, Moduri and Hadejia in Jigawa state. In Niger Republic, the major groups of dialects of Kanuri are Bilma, Dagora and Manga. Kanuri is spoken by quite a large majority of people in the area stretching from Zinder in the west down to the Lake Chad region. In the republic of Cameroon also live a substantial number of Kanuri speaking community in the towns of Kolofata, Marwa, Kusuri, Mokolo and Ngaoundere Bulakarima and Shettima (2012).

Postpositions can be defined as a grammatical classification of words, referring to the closed set of items (noun phrases or single nouns or pronouns) to form a single constituent structure. In English such particles occur before the noun or noun phrase they modify while in Kanuri such similar particles occur after the noun they modify and for this reason they are referred to as postpositions (Crystal, 2008, Gazali 2007; 2014). Previous studies on Kanuri postpositions show that postpositions are affixes usually suffixed to nouns, pronouns, adjective etc to express different functions Gazali (2007) examines the different functions of the postposition -ro using Kanuri written text as source, Ziegelmeyer (2008) discusses an aspect of adverbial subordination of Arabic loan words in Kanuri. Gazali and Munkaila (2016) examine the relationship between the postpositions -ro and -lan with their host/ stem -where the study establishes that the postpositions -ro and -lan are clitics not affixes. However, none of these studies identifies subordination and grammaticalization introduced by the postpositional particles $=\mathrm{ga}$ and $=\mathrm{ma}$ in Kanuri as either affix or clitics. Therefore this paper examines grammaticalization of some of these postpositional particles =ro, =lan, =ga and =ma in Kanuri using Kanuri written texts as source of data.

\section{Literature Review}

Cyffer (2015) observes that in Kanuri, clause subordination is usually done by enclitics or postpositions which have evolved functionally from other categories. Cyffer (2015:8) provides table display of Kanuri formative and subordination in the following table (1) below:

Table 1.

\begin{tabular}{|c|c|c|c|}
\hline Form type & functions & level & Approx. meaning \\
\hline -ro Enclitic & $\begin{array}{l}\text { Basic function: Direction } \\
\text { Indirect object } \\
\text { Adverb } \\
\text { Benefactive } \\
\text { Cause \& Reason } \\
\text { Clause: cause \& reason } \\
\text { Clause: Intension }\end{array}$ & $\begin{array}{l}\text { phrase } \\
\text { clause } \\
\text { phrase } \\
\text { clause } \\
\text { phrase } \\
\text { clause } \\
\text { Clause }\end{array}$ & $\begin{array}{l}\text { 'for' } \\
\text { 'because of' } \\
\text { 'because' } \\
\text { 'in order to' }\end{array}$ \\
\hline
\end{tabular}

The table (1) above shows that the postposition -ro as bound morpheme encliticized to phrases and clauses in Kanuri to express directional, indirect object, adverb, benefactive, adverbial phrase of cause and reason, adverbial clause of reason and cause and adverbial clause of intension in Kanuri. However, the study falls short of descriptively explaining the relationship between the hosts/ stems they are attached with. Therefore, this paper examines their relationship using analytical model adopted by Luis and Spencer (2012) as theoretical approach.

Cyffer (2005) identifies postposition -lan encliticized to phrasal constituents to express different strategies and concepts in Kanuri consider the following table (2) below. 
Table 2.

\begin{tabular}{|c|c|c|c|c|}
\hline Form type & type & functions & level & Approx. meaning \\
\hline$-n$ & Enclitic & Basic function: location & phrase & 'at' \\
\hline & & Origin & phrase & 'from' \\
\hline & & Instrument & phrase & 'with' \\
\hline & & Manner & phrase & 'with' \\
\hline & & Clause: Temporal & phrase & 'while' \\
\hline
\end{tabular}

The table (2) above shows that the postposition $-\mathrm{n}$ which is variant of $=$ lan as bound morpheme encliticized to phrases to express adverbial phrase of origin, instrument, manner and adverbial clause of time in Kanuri

Cyffer (2005) also identifies -ga particle encliticized to phrasal and clausal elements to express different strategies and concepts in Kanuri. Consider the table (3) below.

Table 3.

\begin{tabular}{llcc}
\hline Form type & functions & level & Approx. meaning \\
\hline -ga Enclitic & Basic function: Deixis & phrase & 'with regard' \\
& Direct object & clause & \\
& Associative & phrase & 'having' \\
& Clause: conditional & sentence & 'if' \\
& NP coordination & phrase & 'and' \\
& Clause: Dependent future & sentence & Anteriority \\
& Clause: dependent past & sentence & Anteriority \\
\hline
\end{tabular}

The table (3) above shows conditional marker -ga encliticized to phrases and sentences to express conditional clauses, anteriority and subordinate clauses in Kanuri but the study fall short of explaining the relationship between the conditional marker =ga as clitic with their host/ stem

Cyffer (2014) identifies the emphatic enclitic particle =ma cliticized to nouns to express indefinite affirmative and concessional clauses in Kanuri. Consider the table 4 below.

Table 4.

\begin{tabular}{llll}
\hline Form type & functions & level & Approx. meaning \\
\hline -ma Enclitic & $\begin{array}{l}\text { Basic function: Indifinite } \\
\text { Determiner (aff.) } \\
\text { Clause:concession (neg.) }\end{array}$ & phrase & 'no one' \\
& Sentence & 'though' \\
\hline
\end{tabular}

Table (4) above shows emphatic particle =ma cliticized to nouns and determiners to express indefiniteness and concessional clauses in Kanuri but this study falls short of discussing main grammatical function of emphatic marker $=$ ma as focus marker in Kanuri.

Previous studies on the postpositions in Kanuri (Koelle 1854), (Lukas 1937), (Hutchison 1976), (1981), Cyffer (1983), (1991), (1998) Bulakarima and Shettima (2012) observe relationship between the postpositional particles suffixed to nouns, pronouns, adjectives, adverbs to express different functions. Cyffer (2015) Gazali and Usman (2012) opine that postpositions -ro and -lan can be clitics and affixes in Kanuri when they are suffixed or clticicized to nouns, verbs, adjectives and pronouns in Kanuri but their study fall short of examine the relationship between the hosts and their stems. Gazali and Munkaila (2016) further examine relationship between the postpositions and their host/ stem relationship adopting Spencer and Luis (2012). The outcome of their study reveal that -ro and -lan are clitics not affixes. Therefore this paper examines grammaticalization of some 
postpositional particles - ro, - lan, conditional marker $=\mathrm{ga}$ and emphatic marker $=\mathrm{ma}$ as enclitics in Kanuri using two different Kanuri written texts.

Gazali and Munkaila (2016) discuss the relationship between the postpositions -ro and lan and their relationship to their host (s) and stem (s). Their study reveals that the postpositions are attached to virtually every lexical category in Kanuri. Their analysis adopted works of Zwicky and Pullum (1983) and Spencer and Luis (2012) as model of approach and Theoretical framework.. Gazali and Munkaila (2016:291) identify the followings as clitics in Kanuri:

(i) Indirect object marker -ro as clitic

(ii) Temporal -ro as clitic

(iii) Intension -ro as clitic

(iv) Temporal -(la)n as clitic

(v) Instrument - (la)n as clitic

\section{Research Methodology}

In conducting this research, primary sources of data collection was employed. The source of data includes the text Səmonəm wuro sarugəsəne and Nyariwa Kanuribe . In the texts all the various places where the Postpositions -ro, -lan, emphatic marker =ma and conditional particle =ga occurred were identified, underlined and extracted from the two texts for data presentation and analysis. Our choice of these texts was informed by the popularity of the two books which were all written with the principles of Standard Kanuri Orthography (SKO). We considered the whole text no lottery method was used in picking the data.

\section{Theoretical Framework}

The approach adopted for this study is mainly a descriptive approach adopting the works of Zwicky and Pullum (1983), Anderson (2005) and Spencer and Luis (2012) as its analytic models. We adopted these approaches because the attachment of the these morphemes or particles $=$ ro, =lan, =ga and =ma are more of clitics than affixes.

Zwicky and Pullum (1983) propose six criteria for distinguishing clitics from affixes:

(i) Host selectivity: clitics can exhibit a low degree of selection with respect to their hosts while affixes exhibit a high degree of selection with respect to their stems.

(ii) Arbitrary gaps in the of combinations are more characteristics of affixed than clitic groups.

(iii) Morph-phonological idiosyncrasies are more characteristics of affixed words than of clitics. Morphophonological alternation means forms that are not the result of completely regular phonological processes. All clitics have low tone but attachment will not change the tonal pattern but affixes change.

(iv) Clitics-affix ordering: clitics can attach to material already containing clitics but affixes cannot.

Anderson (2005) discusses syntactic theories of clitic placement where he identifies three important positionings of special clitics that allocates this task entirely to the syntax. These are;

(v) Strong syntax: Clitic positioning is fully determined by the syntax. 
(vi) Strong Phonology: phonology is fully responsible for placing clitics in the second position. The syntax generates clitics in normal argument positions.

(vii) Weak syntax: most movement of clitics is syntactic. However, prosodic inversion may intervene in the phonology to satisfy the requirement of a clitic for an appropriate host.

Spencer and Luis (2012) examine clitics placement in terms of the second position. Where they define clitics placement in linear terms, in which case it means 'after the first accented word'. Or it can be defined in structural terms, in which case it means 'after the accented phrase' The placement of these particles -ga, -ro, -lan and -ma are placed after the right edge of the first phrase or word. This terminology of 'after the first accentuated phrase' was introduced by Halpern (1995). Halpern (1995) observes that placement after the right edge of the first phrase of the clause is called 2D placement ('2D' for 'second (constituent) daughter'), while placement after the first (full, phonological) word is called $2 \mathrm{~W}$ placement (' $2 \mathrm{~W}$ ' for 'second word'). We shall see how genitive marker =be as clitic allows alternate freely between $2 \mathrm{~W}$ and $2 \mathrm{D}$. The genitive marker $=$ be as clitic has a wide range of syntactic functions. It can occur after the first full phonological word in Kanuri (see Gazali \& Gombe 2020) as illustrated in the examples below.

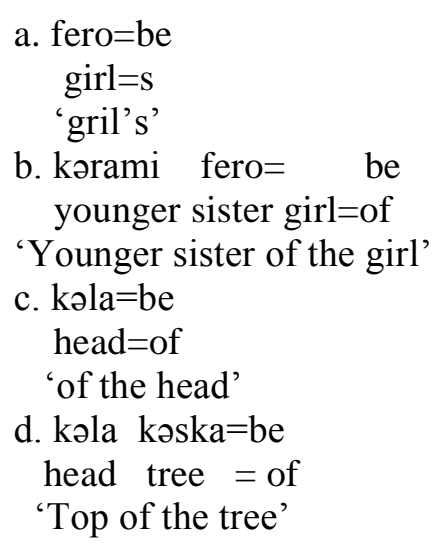

The above examples in (1a and b) show the placement of the genitive marker after the first accented word -cliticized to the noun 'fero' (girl) while in examples ( $1 \mathrm{c}$ and $\mathrm{d}$ ) the placement after the right edge of the first phrase or 2D placement -the genitive marker =be cliticized to the noun 'kəla' (head) and in (1d) cliticized to 'kəska' (tree). The sentences express different syntactic and semantic functions.

The study adopts the framework of Zwicky and Pullum (1983) and Anderson (2005) Aspects of the Theory of Clitics theoretical approach in analyzing the data collected from the two texts.

\section{Data Presentation and Analysis}

\subsection{Data Presentation}

In the texts analyzed, this study identified two thousand four hundred and eighty-one postpositional clitics in written Kanuri texts. The different syntactic functions of the grammaticalised postpositions =lan and =ro, conditional marker $=$ ga and emphatic marker $=$ ma as clitics were identified in the two written Kanuri texts. The postpositions =ro and 
$=$ lan, the conditional marker $=\mathrm{ga}$ and the emphatic markers are bound morphemes attach to different word class in Kanuri. This study examines the relationships between these markers and their host (s) using affixes and clitics relationship and established that these morphemes are clitics by virtually cliticizing to every grammatical category in Kanuri using simple percent of their occurrence in the table (5) below.

In order to calculate the percentage of their occurrences, we use the formulae below:

POP - ro and - lan $=N R L C \div T N P C \times 100$

Where: POP is the percentage of the occurrences of -ro and =lan as clitics

NRLC is the Number of -ro and -lan as clitics in the two texts

TNC is the total number of postpositional clitics in the two texts

The table (2) below shows the different types of postpositional clitics found in the two texts with their number of occurrences and percentages.

Table 5. postpositional particles =lan, =ro, =ga and =ma as clitics found in the two texts

\begin{tabular}{clcc}
\hline & The postpositional enclitics & $\begin{array}{c}\text { Number of their } \\
\text { occurrences in the text }\end{array}$ & $\begin{array}{c}\text { Percentage of their } \\
\text { occurrences in the text }\end{array}$ \\
\hline 1 & Postpositional =ro and =lan & 1462 & $58.93 \%$ \\
2 & Conditional clitic =ga & 647 & $26.08 \%$ \\
2 & Emphatic clitic =ma & 372 & $14.99 \%$ \\
$\quad$ Total & 2481 & $100 \%$ \\
\hline
\end{tabular}

The above table (5) shows the number of the occurrences of the postpositional enclitics in the text analyzed with their number of occurrences and their percentages. The analysis shows that the postpositional clitics =ro and =lan occur in one thousand four hundred and sixty-two instances with $58.93 \%$, the conditional clitic =ga occurs in six hundred and forty seven instances with $26.08 \%$ while the emphatic clitic =ma occurs in three hundred and seventy-two instances with $14.99 \%$ in the two texts analyzed. The three postpositional enclitics are also analyzed base on their relationship with their hosts/ stems as demonstrated in table $6 \mathrm{a}, \mathrm{b}$ and $\mathrm{c}$ below.

Table 6a. Postpositional particles =ro and =lan as Clitic found in the wo texts

\begin{tabular}{clcc}
\hline & $\begin{array}{c}\text { The postpositional particle =ro and } \\
\text { =lan cliticized to different word classes }\end{array}$ & $\begin{array}{c}\text { Number of their } \\
\text { occurrences in the texts }\end{array}$ & $\begin{array}{c}\text { Percentage of their } \\
\text { occurrences in the texts }\end{array}$ \\
\hline & & 728 & $49.79 \%$ \\
2 & Cliticized to nouns & 368 & $25.17 \%$ \\
3 & Cliticized to verbs & 246 & $16.83 \%$ \\
4 & Cliticized to adjectives & 80 & $5.47 \%$ \\
5 & Cliticized to adverbs & 40 & $2.74 \%$ \\
& Cliticized to pronouns & 1462 & $100 \%$ \\
\hline
\end{tabular}

The table (6a) above shows postpositional particles =ro and =lan cliticized to different word classes in Kanuri texts. The study also identified and analyzed their number of occurrences and their percentages of each word class. The analysis shows that the postpositional particles =ro and =lan cliticized to nouns in seven hundred and twenty two instances with high percentage of occurrences in the text with $49.79 \%$, the postpositional particles =ro and $=$ lan cliticized to verbs in three hundred and sixty eight instances which has $25.17 \%$ of total number of $=$ ro and =lan cliticized to verbs in the two texts analyzed, =ro and $=$ lan cliticized to adjectives in two hundred and fourty six instances with $16.83 \%$, the =ro and =lan particles are also cliticized to adverbs in eighty instances with $5.47 \%$ and finally the 
postpositional particles =ro and =lan are cliticized to pronouns in fourty instances which has the lowest percentage of occurrences in the two texts with $2.74 \%$.

Table 6b. The conditional marker $=\mathrm{ga}$ as clitic found in the two texts

\begin{tabular}{cccc}
\hline $\begin{array}{c}\text { Postpositional particle }=\mathrm{ga} \\
\text { cliticized to different word classes }\end{array}$ & $\begin{array}{c}\text { Number of their occurrences } \\
\text { in the texts }\end{array}$ & $\begin{array}{c}\text { Percentage of their } \\
\text { occurrences in the texts }\end{array}$ \\
\hline 1 & Cliticized to nouns & 416 & $64.30 \%$ \\
2 & Cliticized to pronouns & 196 & $30.29 \%$ \\
2 & 35 & $5.41 \%$ \\
& Cliticized to verbs & 647 & $100 \%$ \\
\hline
\end{tabular}

Table (6b) above shows the conditional marker =ga cliticized to different word classes in texts analyzed. The analysis shows that the conditional particle $=\mathrm{ga}$ as cliticized to nouns in four hundred and sixteen instances with $64.30 \%$, the conditional particle $=\mathrm{ga}$ also cliticized to pronouns in one hundred and ninety six instances which has $30.29 \%$ of the $=$ ga attached to pronouns in the two texts while the conditional particle =ga is cliticized to verbs containing inflectional suffixes in thirty five instances which constitute the lowest percentage of occurrences of $=$ ga cliticized to different classes in the text analyzed with $5.41 \%$.

Table 6c. The Emphatic marker =ma as clitic found in the texts

\begin{tabular}{clcc}
\hline $\begin{array}{c}\text { Emphatic particle =ma cliticized } \\
\text { to different word classes }\end{array}$ & $\begin{array}{c}\text { Number of their occurrences } \\
\text { in the texts }\end{array}$ & $\begin{array}{c}\text { Percentage of their } \\
\text { occurrences in the texts }\end{array}$ \\
\hline 1 & Cliticized to nouns & 289 & $77.69 \%$ \\
2 & Cliticized to pronouns & 78 & $20.97 \%$ \\
2 & Cliticized to determiners & 05 & $1.34 \%$ \\
$\quad$ Total & 372 & $100 \%$ \\
\hline
\end{tabular}

Table (6c) above shows that the emphatic marker =ga cliticized to three different word classes in the two texts analyzed. The analysis shows that the emphatic clitic =ma is cliticized to three hundred and seventy two instances to nouns, pronouns and determiners in the texts. The emphatic =ma occurs in two hundred and eighty nine instances which has the highest number of =ma cliticized to different word classes with $77.69 \%$, the emphatic $=$ ma also cliticized to pronouns in seventy-eight instances with $20.97 \%$ while the emphatic $=\mathrm{ma}$ cliticized to determiners in five instances which has the lowest percentage of occurrence with $1.34 \%$.

\subsection{Syntactic and Semantic functions of the postpositional particles found in the texts}

\section{Postposition -ro and -lan as clitics}

The postpositions -ro and -lan are bound morphemes cliticized to virtually every word in Kanuri. It can be attached to nouns, pronouns, adjectives, adverbs, conjunctions and verbs. In the texts analyzed, we observed strategies and concepts of postpositions as adverbial subordination in the text. 


\section{Postposition -ro as adverbial subordination in Kanuri}

\section{-ro as reason and cause}

The postposition -ro can function as a subordinating conjunction in Kanuri with the sole meaning of expressing reason and cause. Consider the following example below.

1. a. Hal ngəla- nəm=ro, dagəl zəwuru nandi-ro kedio

habit good-your=REC monkey migrated us-DOM he came Because of your good habit, monkey migrated and joined us' 'Monkey migrated and joined us because of your good habit'

b. kərmu sawa-nzə -be= ro, bəla sawa -nzə -ro taji- ro lewono death friend-his-Gen=REC town friend-his-DIR condolence-INF he went Because of the death of his friend, he went to his friend's town to condole them' He went to his friend's town so as to condole them'

The above examples in (1a and $\mathrm{b}$ ) above show that the postposition -ro introduces reason and cause. The morpheme -ro (because) serves as subordinating conjunction between the two clauses. The underlined clauses are dependent clauses that cannot stand on their own to constitute a full sentence unless attach to an independent clause as shown in examples (1a and b) above.

\section{-lan as temporal clause}

The postposition -lan can function as subordinating conjunction in Kanuri with the sole meaning of expressing time and adverbial clause of time. Consider the following examples in $(2 \mathrm{a}$ and $\mathrm{b})$ below.

2. a. kawu gana -be ngawo=n kwa nui day small-GEN after=TEM husband died

After few days, the husband died

'The husband died after few days'

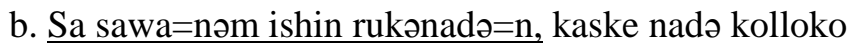

Time friend=your coming saw-RTV=TEM ran place the I left

By the time I saw your friend coming, I rushed and left area'

I left the area by the time I saw your friend coming'

The above examples in ( $2 a$ and $b$ ) show that the postposition -(la)n functions as temporal phrase and clause in Kanuri.. Here, there are two clauses: dependent and independent clauses. Strategically, the temporal -ro links the two clauses and encliticized to adverb 'after' (ngawo) in example (2a) and in example (2b) the temporal -ro is encliticized to the verb (rukəna) which already contains inflectional past tense marker '-na' suffixed to the verb root and the relativizer ' $\mathrm{d} ə$ ' is cliticized to past tense inflectional suffix while the temporal postposition $=\mathrm{n}$ is encliticized to the relativizer to express adverbial clause of time in Kanuri.

\section{Subordination in Kanuri}

3. a. Temporal simultaneity 
[tarmuna fomjin duwu] na bultu=be=ro kedio

[ Rabbit while he was walking about], He came to the place of hyena'

b. Temporal anteriority

[ngawo dagəl isəna=be=n] fato=nza=ro leyada]

[After monkey had arrived], they went to their house

c. c.Intension

[buri mata=ro kəmbu=ro] dagəl ciluwo

[So as to look for food] monkey went out

d. Cause and reason

[wu-ga maajin=ro nongənyi] ba mata=ro lewoko

[I don't know he was looking for me] I went out to look for food

\subsection{Conditional marker-ga as clitic in Kanuri}

Conditional clauses are part of sentences, which express factual implications, or hypothetical situations. Their consequences are expressed in the main clause (Cyffer and Bulakarima (Manuscript). The formative of the conditional clause can exhibit element of enclitics than suffix. Consider the following examples below:

3 a. bəri zəwin=ga kasuwu=ro lejinba

food eating=CM market-DIR he will go NEG

'If he has not eaten food he will not go to the market'

b. bəri mbeji=ga wu=ro mananuwu food exist=CM me-IOM you talk

'If there is food you should talk to me'

c. Maiji=ga shi=ga gaskin

king= CM him=DOM I will pay my allegiance

'On my you become our king I will pay my allegiance to you'

d. sawa-nyi biska isə= nyi=ga karəgə-nyi zauro kuttu friend-my yesterday come $\mathrm{NEG}=\mathrm{CM}$ heart -my very sad

''If I hadn't seen my friend yesterday, I had been very sad'

The above structure in ( $3 \mathrm{a}, \mathrm{b}$ and $\mathrm{c}$ ) above show that the conditional marker $=\mathrm{ga}$ as cliticiticized to verbs in examples ( $3 a$ and b), in example ( $3 c$ ) is cliticized to noun 'king" while in (3d) it cliticized to negation particle - nyi and the conditional marker $=$ ga as clitic also cliticized to the negation particle to express conditional clauses in Kanuri. (more on negation as clitics in Kanuri see Munkaila \& Gazali 2017 The morphosyntax of negation markers in Kanuri.

\subsection{Emphatic clitic $=$ ma}

The emphatic clitic =ma is used as focus marker in Kanuri. Crystal (2008) defines focus as a term used by some linguists in two-parts analysis of sentences which distinguishes between the information assumed by speakers and that which is at the centre (or 'focus') of their communicative interest; 'focus' in the sense is opposed to presupposition. In the sense, it is the contrast between given and new information makes an analogous distinction. The study observed that the emphatic particle =ma encliticized to nouns, pronouns and 
determiners to distinguish between two information given. Let consider declarative and focus structure in ( $4 \mathrm{a}$ and $\mathrm{b})$ below.

4. a. Ali fuwura

'Ali is a student'

b. Ali=MA fuwura

Ali=EMP student

'It was ALI who is a student'

c. dagal abi zəwo

'monkey what he ate'

'What did monkey eat'

d. Dagəl abi=ma zəwunyi

Monkey what=EMP

'Monkey did not eat anything'

The above structure in (4a, b, c and d) show the emphatic clitic =ma as focus particle can be cliticized to subject NP in examples (4a and b) while in (4d) ma cliticized to object NP.

\section{Conclusion}

This paper has examined the postpositional particles =ro and =lan, emphatic marker $=$ ma and the conditional marker -ga in Kanuri using two written texts as sources of data collection. These particles are syntactically and morphologically attach to virtually grammatical word classes in Kanuri. The study identified two thousand four hundred and eighty-one postpositional enclitics =ro, =lan, =ga and =ma in the two texts analyzed and each of the postpositional enclitics were further analyzed base on their relationship with their hosts/ stems. The outcome of the study reveals that the postpositional particles $=$ ro, =lan, =ga and =ma are encliticized to different to different grammatical categories in Kanuri -nouns, verbs, adjectives and pronouns to express different syntactic and semantic functions. These categories of particles are bound morphemes that cannot stand on their own but rather attach phonologically or lean to their proceeding words. Each of the postpositional particle was further examined in relation with their grammatical categories that are cliticized with. The outcome of the study reveals that postpositional particles =ro and =lan occur with highest number and frequency of occurrences with one thousand four hundred and sixty-two instances with $58.93 \%$ of the total postpositional particles found in the two texts. The study further observed that the postpositional particles encliticized to nouns in seven hundred and twenty-eight instances, to verbs in three hundred and sixtyeight instances, to adjectives in two hundred and fourty six instances, to adverbs in eighty instances and finally to pronouns in fourty instances. This data also confirms to the work of Gazali and Munkaila (2017) =ro and =lan as clitics in Kanuri. The conditional particle =ga followed second in terms of number of occurrences in the texts analyzed which occur in six hundred and fourty seven instances with $26.08 \%$. The study also observes that the clitic =ga encliticized to three different word classes in Kanuri -nouns, pronouns and verbs which is less compare to =ro and =lan in terms of number of occurrences while the emphatic clitic $=$ ma occurs in three hundred and seventy-two instances with $14.99 \%$. The emphatic clitic $=$ ma also encliticized to three different word classes -nouns pronouns and determiners in the text analyzed. The promiscuous attachment of these particles is a clear characteristic of clitics than an affix. Clitic selects different word classes while affix is limited to number of 
word class it selects. Finally, the paper examines grammaticalization of the postpositions =ro and =lan as clitics expressing clause subordination and conjunction, the conditional subordination and emphatic $=\mathrm{ma}$ as focus marker in Kanuri.

\section{References}

[1] Anderson, S. R. (2005). Aspects of the Theory of Clitics (No. 11). Oxford University Press on Demand.

[2] Bendo, M.L. (2000) “African languages". In: Heine and Nurse (ed.) Pp 43-73

[3] Bukar, S. \& Hutchison, J.P. (1978). Nyariwa Kanuribe. Northern Nigerian Publishing Company Ltd.

[4] Bulakarima, S.U. \& Shettima, A.K. (2012). A Sketch of Kanuri Phonology and Tone. Desktop Publishers cooperative Society, Maiduguri.

[5] Crystal, D. (2008) A Dictionary of Linguistics and Phonetics. Sixth edition Basel Blackwell, UK.

[6] Cyffer, N. (1998). A sketch of Kanuri (Vol. 9). Rudiger Koppe..

[7] Cyffer, N. (1979). Səmonəm Wuro Sarusəgəne. Lagos. Thomas Nelson.

[8] Cyffer, N. (1983). The Standard Kanuri Orthography. Kay Williamson (ed.), Orthographies of Nigerian Languages. Manual 2, Lagos: National Language Centre (Federal Ministry of Education), 30-45.

[9] Cyffer, N. (1991). We learn kanuri. Koln RudigerKoppeVerlag

[10] Cyffer, N. (2005) Strategies and Concepts of Subordination in Kanuri. In: G.C. Batic \& S. Baldi (ed.) Selected proceedings of the west African languages. Napoli Pp 41-63 (2014) year of publication not 2005

[11] Gazali, B.K.A. \& Munkaila, M. (2016). Negative Markers in Kanuri: A Morphosyntactic Analysis of Nyariwa Kanuribe. Journal of Linguistics, Language and Culture. Nnamdi Azikwe University, Awka, Nigeria. Volume 4 N0 3 2016. Pg 45-52.

[12] Gazali, B.K.A. \& Usman, B. (2012). Postposition -ro and -lan as Clitic and Affix in Kanuri. International Journal of Research in Linguistics \& Lexicography: INTJ. Bahauddin Zikriya University, Mutan Pakistan

[13] Gazali, B.K.A. (2007) A Descriptive Analysis of the Various Functions of the Postposition -ro in Kanuri.Unpublished M.A. dissertation, Department of languages and linguistics, University of Maiduguri.

[14] Gazali, B.K.A. (2014) Descriptive Analysis of the Various Functions of the Postpositions in Kanuri. Unpublished $\mathrm{PhD}$ Thesis, Department of languages and linguistics,University of Maiduguri.

[15] Gazali, B.K.A. (2020) 'Determiner and Genitive markers as Second Position Clitics in Kanuri”' In : Abdul (ed.)Yankari Journal of English, Literature and Linguistics, Bauchi StateState University, Gadau.

[16] Greenberg, J.P. (1963).The languages of Africa. The Hague.

[17] Halpern. A. (1995) On the Placement and Morphology of Clitics. Dissertations in Linguistics Stanford. CA: CSL1 Publications

[18] Hutchison, J.P. (1976). Aspects of Kanuri syntax. Unpublished Ph.D Thesis, Indiana University, Bloomington.

[19] Hutchison, J.P. (1981). The kanuri language. a reference grammar. Madison: University of Wisconsin,U.S.A.

[20] Koelle, S.W. (1854). Grammar of Bornu or Kanuri Language. London: Church Missionary House.

[21] Lukas, J. (1937). A Study of the Kanuri Language and Vocabulary. London: Oxford University Press.

[22] Munkaila, M. \& Gazali, B.K.A. (2016) "Postpositions -ro and -lan as Clitic in Kanuri" In: Omachonu and Taiwo (ed.) Journal of Linguistics Association of Nigeria (JOLAN) Supplement N0. 1 Pp 160-165.

[23] Spencer, A. \& Luis, A. (2012).Clitics an introduction. London Cambridge University Press. 
[24] Ziegelmeyer, G. (2008) “Aspects of Adverbial Subordination in Kanuri”. In: Maiduguri Journal Of linguistics \& literary studies MAJOLLS. University of Maiduguri.Vol.X Pg 16-17.

[25] Zwicky, A. and Geoffrey, K. Pulum (1983) Cliticization vs Inflection: English n’t Lg. 59.502-13. 